\title{
ANALYSIS OF THE DEGRADATION CONDITION OF SECONDARY SCHOOLS. CASE STUDY: PAVILIONS AND PREFABRICATED BUILDINGS
}

\author{
Joana BARRELAS, Jorge DE BRITO, João Ramôa CORREIA \\ Department of Civil Engineering, Architecture and Georesources, Instituto Superior Técnico, \\ Technical University of Lisbon, Av. Rovisco Pais, 1049-001 Lisbon, Portugal
}

Received 26 Apr 2013; accepted 16 Sep 2013

\begin{abstract}
This paper presents the analysis of the degradation condition of secondary schools built between 1970 and 1990, in Portugal. The analysis is based on 15 case studies, mainly composed of several independent pavilions and typologically defined as "pavilion schools". The analysis of the data on the constructive defects, identified in detailed surveys of the case studies and registered in technical reports, involves the implementation of a suitable methodology. The methodology is based on the creation of a database where the contents of the survey reports can be gathered and organized. The system allows obtaining statistical results on the degradation condition of the case studies. The statistical analysis shows that the pathological condition of the buildings is a matter of great concern, considering the significant number of defects diagnosed. The highest level of severity mainly concerns defects on the buildings envelope, where concrete elements are the most affected ones. The degradation conditions of the case studies are mostly a consequence of the poor construction quality resulting from decisions made during design and construction. The economic constraints and the tight schedule concerning the expansion of secondary school facilities are also essential to understand the pathological condition of the buildings. The study presented in this paper contributes to the evolution of the methods and systems developed to support buildings' rehabilitation. The study presents innovative features related to the typology of the case studies (large secondary schools) and to the buildings' degradation condition.
\end{abstract}

Keywords: secondary school, pavilion, constructive defect, database, degradation condition and rehabilitation.

\section{Introduction}

The total number of secondary schools built in Portugal since the end of the 19th century is approximately 500 (Nunes, Heitor 2010). Among these the ratio of schools built after the end of the 1960's is 77\%. Furthermore, $46 \%$ of existing schools were built during the 1980's and these schools are composed essentially of pavilions and prefabricated buildings.

The considerable expansion of Portuguese secondary school facilities that took place after 1968, the growing student population and the increasing maintenance budgets restrictions, all have contributed to the continuous degradation of school buildings. In fact, in these buildings, not only defects tend not to be subjected to the required corrective actions, but also buildings tend to become inadequate for the current comfort and accessibility requirements and also the most recent learning techniques (Heitor 2009).

This paper presents the analysis of the degradation conditions of 15 secondary schools, built in Portugal between 1970 and 1990, based on the implementation of a methodology developed for that purpose. The buildings are analysed according to their condition before the improvements achieved with the implementation of the secondary schools modernization program started in 2007 and developed by Parque Escolar, E.P.E.

The case studies are pavilion schools, essentially composed by a set of independent pavilions that are usually connected through external roofed paths (Fig. 1). These schools include a pavilion of a given type that includes mostly the teaching areas and is repeated a number of times in the school perimeter. In this pavilion, the classrooms are peripherally disposed around the staircase core. The centre of the pavilion has natural lighting from the roof. A pavilion school is also composed of other kinds of pavilions that integrate non-teaching areas, such as the multipurpose room, the cafeteria and the canteen (Alegre et al. 2010).

The case studies (15 schools) are organized in four main groups. "Sub-typology A" includes the buildings resulting from the standard project developed for secondary schools in 1968 (Fig. 2a, 5 schools built between 1972 and 1980). "Sub-typology B" includes the schools derived from the standard projects developed between 1960 and 1966, in order to build technical schools (Fig. 2b, 4 schools - 1970 to 1983). "Sub-typology C" includes the

Corresponding author: Joana Barrelas

E-mail: joana.barrelas@gmail.com 


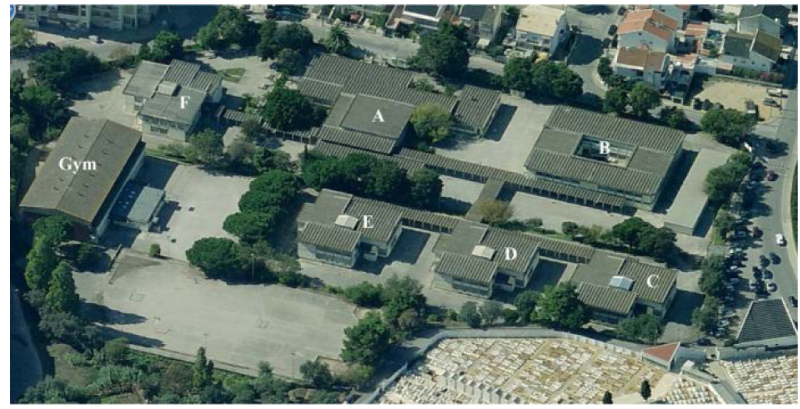

Fig. 1. Aerial view of one of the pavilion schools analysed (Branco et al. 2008; Virtual Earth)

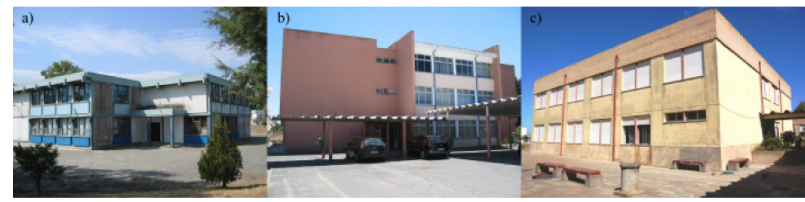

Fig. 2. Pavilion-type characteristic from sub-typologies a) A; b) $\mathrm{B}$; and c) $\mathrm{C}$

buildings based on the "Project $3 \times 3$ " developed in the beginning of the 1980's by the "General Directorate of School Buildings" (Fig. 2c, 5 schools - 1982 to 1990). "Sub-typology D" includes schools with pavilions mainly built with prefabricated systems, such as the CLASP system (first implemented in 1957, in the United Kingdom, through the initiative of the Department of Education) (3 schools, 1975 to 1976).

The structure of the pavilions from sub-typologies $\mathrm{A}, \mathrm{B}$ and $\mathrm{C}$ is generally composed by a set of reinforced concrete frames and cast-in-situ or lightweight slabs (Branco et al. 2008). Before 1983, the pavilions belonging to "sub-typology C" usually integrated columns and waffle slabs (Alegre 2009). Concrete elements, most of them structural, are present in the facades of the pavilions. The pavilions belonging to "sub-typology A" are topped with reinforced concrete beams and panels resting on bearing elements.

The pavilions' roofs are generally flat, coated on the outside with a waterproofing system applied over prefabricated concrete slabs, or pitched, covered with corrugated fibrocement roof plates or with metallic panels. The skylights have a metallic structure over which translucent panels rest (Branco et al. 2008). At a later stage of "Project $3 \times 3$ ", the roof of the pavilions has an elevated flat slab at the centre that allows natural lighting through lateral windows (Fig. 3).

In all sub-typologies the walls are not structural and are made of double and simple masonry panes on the buildings' envelope and interior, respectively. These partition walls are mostly rendered and painted (Branco et al. 2008).

Regarding the schools included in "sub-typology D", the structure of the pavilions consists of a set of frames made of steel profiles and trusses (Fig. 4). The slabs and the external walls are built with prefabricated reinforced concrete panels. The inner side of the facade is

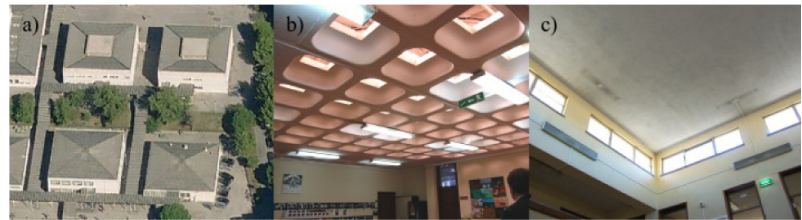

Fig. 3. Secondary school from sub-typology C: a) aerial view of two different roof solutions; b) interior view of the central circulation area illuminated by skylights; c) lateral windows

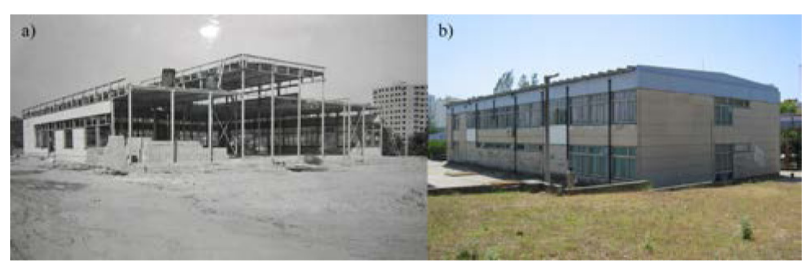

Fig. 4. Secondary school from sub-typology D: a) Pavilion construction using CLASP system, (Sorefame Portugal);

b) View from the exterior of the pavilion

made by wood-based panels or wood particle and cement panels (Branco et al. 2008).

The constructive features of the buildings and the circumstances behind the design and construction processes complement the analysis of the defects diagnosed in the case studies. This information is important to understand their degradation conditions.

\section{Methodology}

The development of methodologies to support the process of inspection, diagnosis and rehabilitation is becoming increasingly relevant, considering the evolution expected for rehabilitation activities within the construction industry. Professionals working in this sector can benefit from such tools in the decision-making process, allowing to efficiently solve the problems related to buildings degradation.

The method developed to analyse the degradation conditions of secondary schools is based on a database using a spreadsheet. This allows processing data registered in the expert reports about the buildings and their defects. The completion of the database file is followed by a statistical analysis. Part of the analysis is based on the establishment of relationships between pathological events and their characteristic parameters. The results indicate the degradation conditions of the case studies.

The database has three main sections related to the following subjects: (1) characterization of the school; (2) location of the building; and (3) diagnosed construction defects. Each section corresponds to a spreadsheet that allows gathering all the information available in the reports on the buildings. The organization of each spreadsheet is based on the tree structure concept, i.e. the general characterization parameters are followed by a set of more specific ones. This is mostly applied to the construction defects section. 
Besides the three sections, the database includes a set of lists. The completion of the database requires the creation of links between some of the entry fields and cells from the lists' spreadsheets. Most of the lists complement the third section, such as the ones with the following contents: construction elements, construction defects, possible causes, functional areas and recommendations for rehabilitation.

The first section of the database focuses on the characterization of the school buildings, regarding their identification, typology, construction date, area, pavilions (including construction characterization) and external surrounding areas (Fig. 5).

The second section is based on the school location. This section includes input fields on the specific location of the building (district, municipality and street). It also integrates parameters related to the buildings' surroundings, exposure and topographic conditions. It was necessary to develop specific criteria to define the levels that better characterize the building location conditions. The building surroundings can be characterized by three levels that vary from an urban context with high density of construction (ME 1) to a more suburban environment (ME 3). The surrounding area is analysed within $100 \mathrm{~m}$ from the school perimeter. The exposure conditions are defined in three levels (EC 1, EC 2 and EC 3) according to the severity of combined climatic factors (rain and wind) in the location of the school. In particular, the exposure conditions depend on the average annual rainfall, as well as the altitude and the distance to the sea. The topographic conditions can be characterized in three levels varying from a plateau (TC 1) to a highly irregular ground (more than $3 \mathrm{~m}$ of variation) (TC 3).

The third section of the database focuses on the characterization of the diagnosed construction defects. This section is the most complex, considering the substantial quantity of data involved, and is determinant for the statistical analysis. Before the characterization of a defect in the database, its specific location must be defined. The defect can be located in external areas or in the building, and in construction elements belonging to

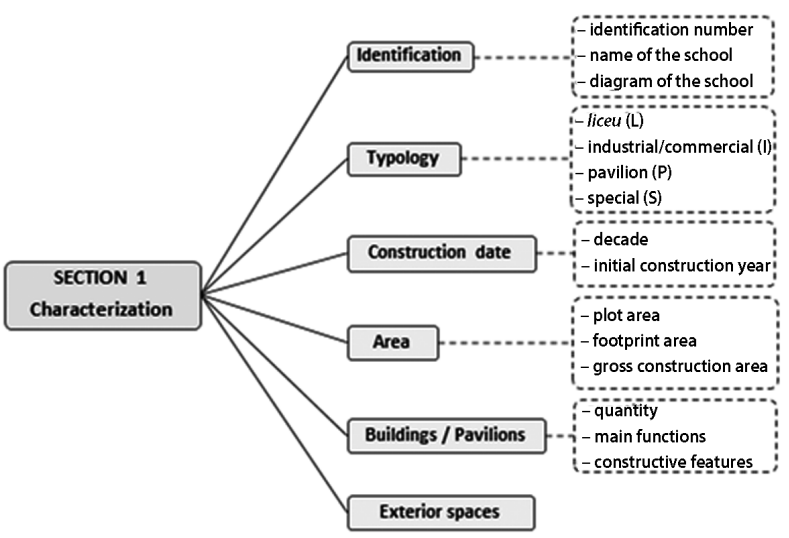

Fig. 5. Organogram of the parameters included in the characterization of the school buildings section its envelope or to its interior (Fig. 6). Subsequently, the entry fields corresponding to the defect's characterization parameters must be filled. These parameters comprise the identification of the type of pavilion and the location of the defect, its possible causes, previous defects, future developments, severity and recommendations for rehabilitation.

The main types of defects that can be diagnosed in the school buildings subjected to inspections are listed in the acronyms list (Appendix). Defects A4 - Mapped cracking and A5 - Oriented cracking correspond to coatings and substrate construction elements, respectively. When oriented cracks occur in coatings the defect code is A5.a). If mapped cracking (A4) or oriented cracking (A5) occur in paintings, the defect codes are A4.b) and A5.b). Both types of cracks (A4 and A5) are registered in the database according to the construction elements in which they are identified. Nevertheless, the same defects must be registered also in all construction elements directly affected. If a crack exists in a masonry wall and also in its rendering, then the defect must be registered in the database for both the substrate construction element and the coating. Defect codes A4.b), A5.a) and A5.b) are thus used to avoid the repetition of defects A4 and A5 and bias of the statistical results.

The possible causes of the defects, also listed in the acronyms list, are organized in six groups, according to their origin: structural $(\mathrm{C} 1)$, environmental $(\mathrm{C} 2)$, related to time/aging $(\mathrm{C} 3)$, related to design or construction (C4), human or animal (C5) and accidental (C6). The causes can also be of an unknown nature (C0).

When a given defect triggers another, it must also be registered using the defect codes presented in the acronyms list. The same codes must be used when the diagnosed defect may cause other pathological events in the future.

The severity of a given defect can be defined according to three levels (1, 2 and 3). Level 1 corresponds to the less severe condition and level 3 to the most severe. The levels of severity are determined in two phases. First the defect diagnosed is characterized by a level of severity according to a set of criteria previously defined through a comparative process. For instance, the level of severity associated to concrete spalling (A8) depends on the area affected by the pathology (particularly for construction elements with a small concrete cover thickness) and on the volume of missing material. Cracks and exposed steel

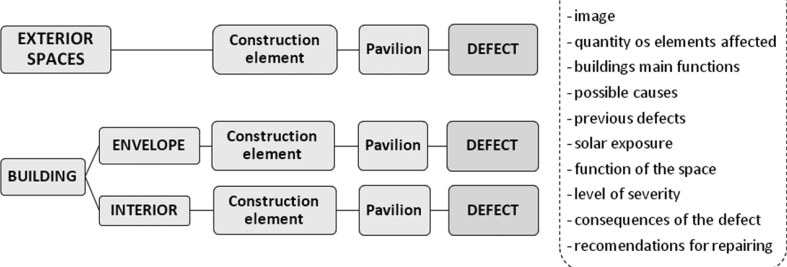

Fig. 6. Organogram of the parameters included in the defects characterization section 


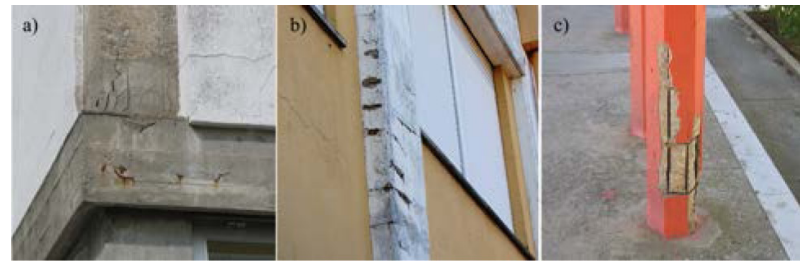

Fig. 7. Illustration of severity levels: a) level 1 - exposed concrete beam; b) level 2 - painted concrete column; c) level 3 - painted concrete column

reinforcement are considered aggravating factors (Fig. 7). After this process, the chosen level is subjected to two types of weighting factors. These factors, also organized in three levels $(1.0 ; 0.7 ; 0.3)$, result from the ranking of the types of defects and construction elements. In terms of types of defects, level 1.0 is associated to those that tend to compromise the safety of the users and the integrity of the building, whereas level 0.3 is used for defects that affect the construction elements only superficially or aesthetically. In terms of construction elements, level 1.0 corresponds to structural elements, while level 0.3 is associated to non-structural elements, including coatings that do not compromise the safety of the users when affected by defects.

The recommendations for rehabilitation described in the reports are based on the preservation of the schools' functional features and original materials (Branco et al. 2008). Improving the construction solutions should be considered when maintaining the original conditions is insufficient to comply with current requirements and also when improving the original conditions is easy and not expensive. The recommendations are listed and organized in groups, according to the type of action or work. The recommendations associated to a given defect must include procedures for the treatment of problems related to the causes. One assumes that the defects must be completely repaired, including all the necessary finishes.

\section{Results and discussion}

The statistical results of the analysis of the case studies allow concluding that the condition of the buildings analysed is a matter of great concern. The number of pathological events diagnosed (2248) is high. Furthermore, $55 \%$ of the defects correspond to the highest levels of severity (2 and 3) (Fig. 8).

The statistical analysis shows that there is a slightly higher number of defects diagnosed in the interior of the schools than in the envelope. However, severity level 3 is considerably more related to pathological events in the buildings envelope (Fig. 9). This condition seems to indicate that the construction elements belonging to the envelope are in worse degradation conditions than the ones from the interior part of the buildings. In this context, it is relevant to refer that approximately $80 \%$ of the concrete elements affected by defects belong to the envelope, while the remaining $20 \%$ are located in the interior. A considerable part of the pavilions is topped with reinforced concrete beams (concrete is mostly exposed or painted). This type of construction element is characteristic of pavilion schools' facades. Considering all the types of elements made out of concrete, this is the one that registers the most significant quantity of defects (Fig. 10).

In all case studies, concrete elements (03) are those most affected by pathological events. Paintings (20), wall coatings (10) and masonry (06) also register a high number of defects (Fig. 11). The most frequently diagnosed types of defects are linear cracking (A5) (in substrate construction elements, coatings and paintings), spalling or flaking (A8) and discoloration or stain (A3).

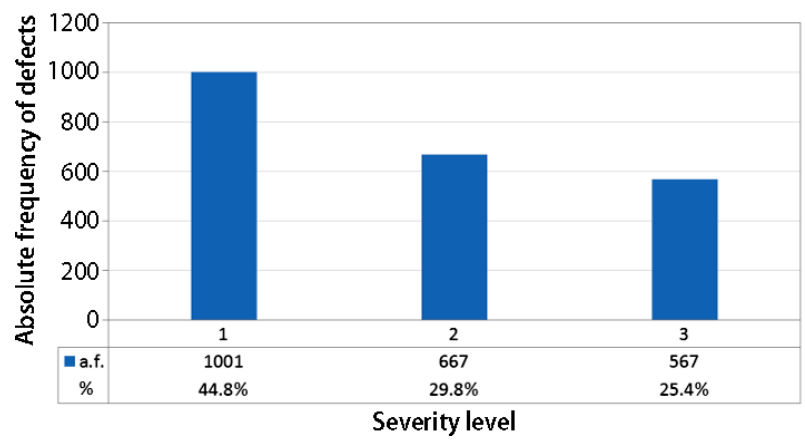

Fig. 8. Absolute frequency (a.f.) and percentage of defects diagnosed, according to their level of severity

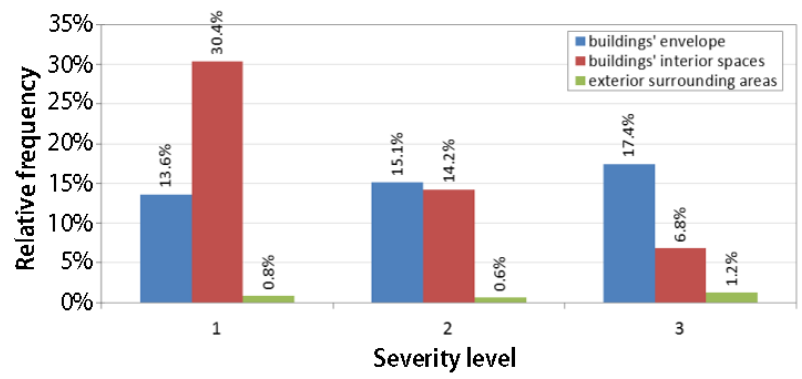

Fig. 9. Percentage of defects diagnosed, according to their level of severity, in the buildings' envelope, in interior areas and in external surrounding areas

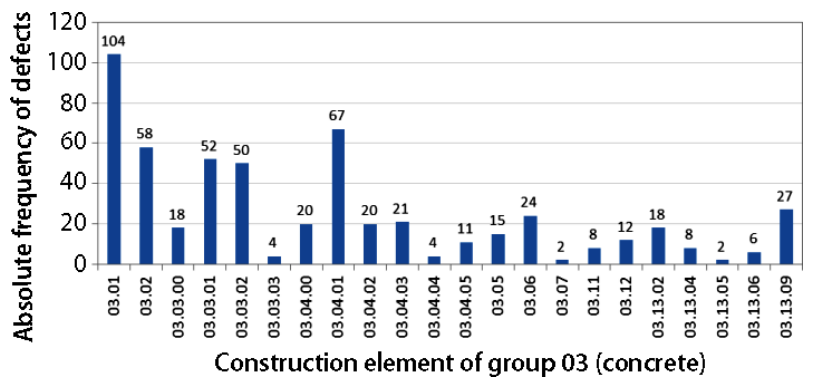

Fig. 10. Absolute frequency of defects according to the specific construction elements belonging to group $03-$ concrete elements 


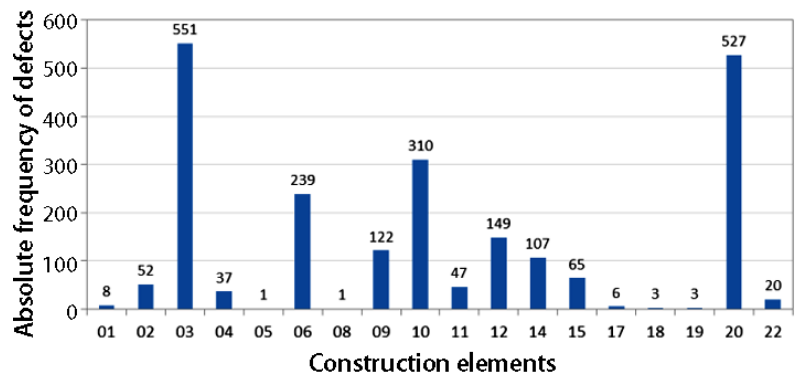

Fig. 11. Absolute frequency of defects according to the construction elements

Part of the statistical results focus on the comparison between the four sub-typologies identified in the set of "pavilion schools". Generally, the results obtained prompt the following comments: (1) due to the remarkable occurrence of linear cracking (A5), including in the connections between partition walls and structural elements, sub-typologies $\mathrm{B}$ and $\mathrm{C}$ denote the need of considerable structural repair work; (2) Sub-typologies A and C, due to the significant incidence of stains (A3), appear to be the ones that require more adjustments in the detailing of the upper peripheral roof elements, in order to avoid water running down the facades; (3) Sub-typology A, due to the predominant occurrence of spalling (A8), seems to be the one that requires more repair related to the treatment and replacement of steel reinforcement in concrete elements; these elements, when structural, may need to be rehabilitated through specific repair techniques, depending on the severity of the spalling and the area of exposed steel reinforcement.

\subsection{Concrete elements}

The presence of oriented cracking and spalling on concrete elements is a matter of great concern (Fig. 12). Frequently, these defects stem from the corrosion of the steel reinforcement and previous problems related to the structural performance of the building. In fact, corrosion of the steel reinforcement is the main previous defect for concrete spalling (A8) (Fig. 13a) and for oriented cracking (A5) in concrete elements (Fig. 13b), basically due to the volumetric expansion of the corroded steel reinforcement.

In this context, it is important to consider the influence of the buildings' exposure conditions on the occurrence of defects in concrete and steel reinforcement. As expected, concrete spalling is identified more often in the buildings' envelope of schools characterized by the most extreme level of exposure. Some of these schools are located less than $5 \mathrm{~km}$ from the coastline. Therefore, the probability of chloride corrosion is higher. Chloride ions are one of the most aggressive agents for concrete structures (Aveldaño, Ortega 2011) and the worst conditions for deterioration caused by chloride attack are found in coastal areas (Takewaka et al. 2003).

According to Figure 13a, oriented cracking (A5) is a relevant previous defect for concrete spalling. It is well

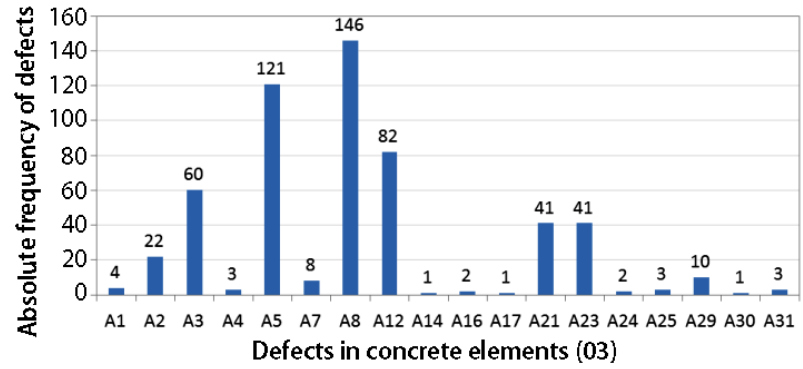

Fig. 12. Absolute frequency of defects in concrete elements
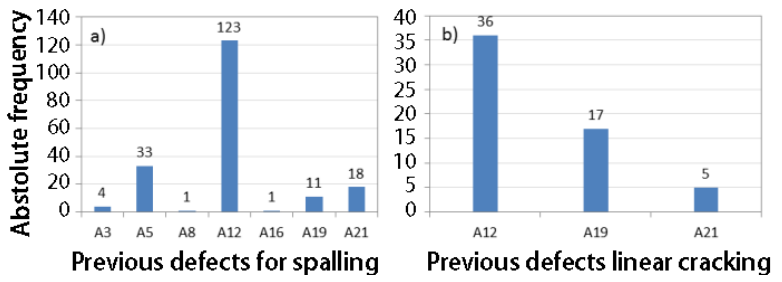

Fig. 13. Absolute frequency of previous defects for a) spalling (A8) and b) linear cracking (A5) in concrete elements (03)

known that cracks over a critical width are likely to influence the penetration of corrosion agents into concrete, such as chloride ions. The diffusion properties of chloride ions are significantly affected by cracks more than $0.1 \mathrm{~mm}$ wide. Takewaka et al. (2003) showed that the shorter the distance from sea, the faster the progress of concrete deterioration is, independently of the water/cement ratio. Therefore, corrosion crack generation also occurs sooner when the concrete elements are closer to the sea.

The corrosion of steel reinforcement, as well as other defects, could have been avoided in the case studies, not only if the concrete cover were well designed and/or guaranteed during construction (for a service life of 50 years, for most types of exposure conditions a cover of 25 to $40 \mathrm{~mm}$ is required, whereas in coastal areas a minimum of 45 to $55 \mathrm{~mm}$ is needed (EN 1992-1-1 2004; LNEC 2005), but also if the concrete construction elements directly exposed to the atmospheric agents were protected. The use of surface protection, such as water repellents, painted rendering or varnish, could have been a possible way of increasing the service life of these concrete elements, provided that regular maintenance was performed. In many cases, concrete cover was below the minimum required and surface protection was often not used. The surface area of exposed concrete and of concrete with degraded painting in facades of the "pavilion schools" in analysis is considerable.

\subsection{Masonry}

Oriented cracking (A5) is the major defect diagnosed in masonry (Fig. 14). Simple brick masonry walls (06.02) and external cavity brick masonry walls (06.01) are the masonry constructive elements (group 06) with the highest number of diagnosed defects (Fig. 15). Oriented cracking (A5) is by far the main type of defect occurring in simple brick masonry walls (06.02). 


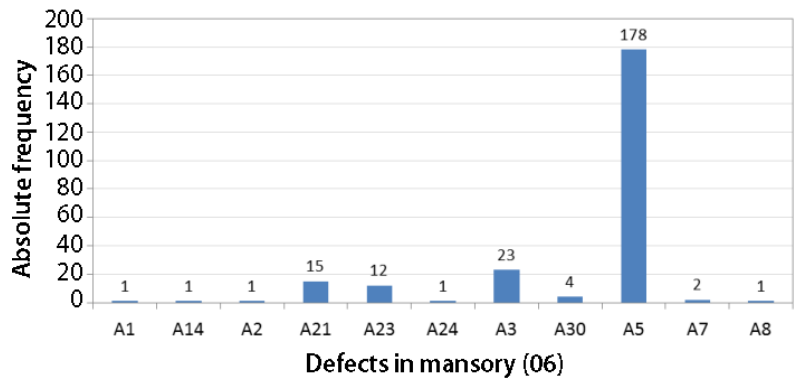

Fig. 14. Absolute frequency of defects in masonry (06)

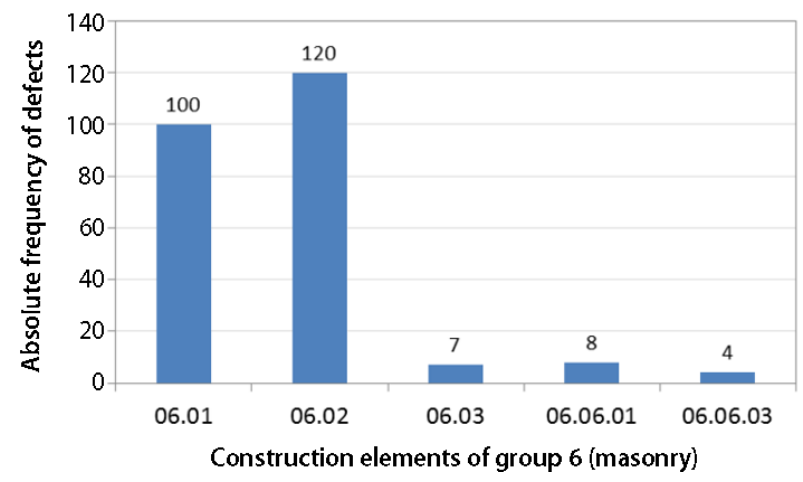

Fig. 15. Absolute frequency of defects according to the specific construction elements belonging to group $06-$ masonry

The occurrence of defects in masonry constructive elements is mostly caused by problems related to the structure of the building (C1) (Fig. 16). Environmental causes (C2) and causes related to the design or construction phases (C4) are also relevant. The specific causes that stand out are differential settlements (C1f), thermo-hygrometric effects (C2a) and excessive stiffness in the connection to other construction elements (C4l) (Fig. 17). These causes are all directly associated to the defect oriented cracking (A5). Temperature variations lead to shrinkage and expansion of walls, adjoining elements and composing materials, creating considerable stresses. Thermal movements of the concrete structure can lead to disconnections between the masonry walls and the structure. The resulting cracks can affect the coating only or, in the most serious situations, the substrate. Minimizing the stiffness in the connection between elements could mitigate this effect. The movement that takes place in all masonry materials, resulting from stress, moisture and temperature change, as well as movements of foundation and adjoining elements, can lead to cracking of the walls (Hendry 2001). As an example, the deflection of supporting beams may induce tensile stresses in the supported walls. Also nonstructural masonry walls underneath beams or slabs may become loaded as a consequence of the deflection of these elements resulting in damage to the walls.

According to Gonçalves et al. (2008), design errors (28\%) and construction errors (29\%) are the main causes of defects in masonry walls, followed by environmental causes $(19 \%)$. It is worth mentioning that in the same

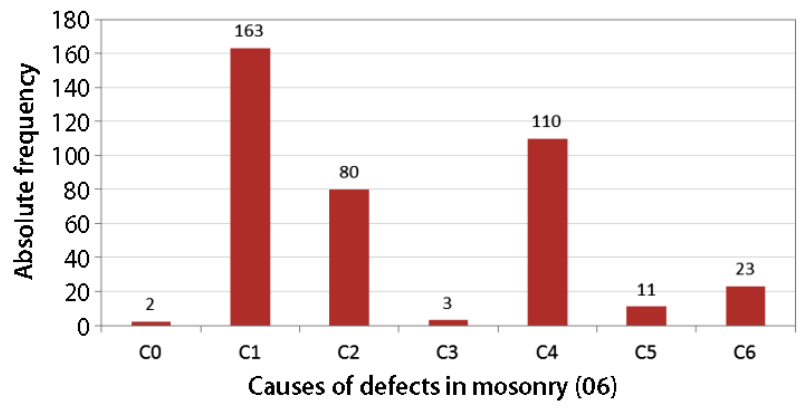

Fig. 16. Absolute frequency of the general groups of causes in masonry (06)

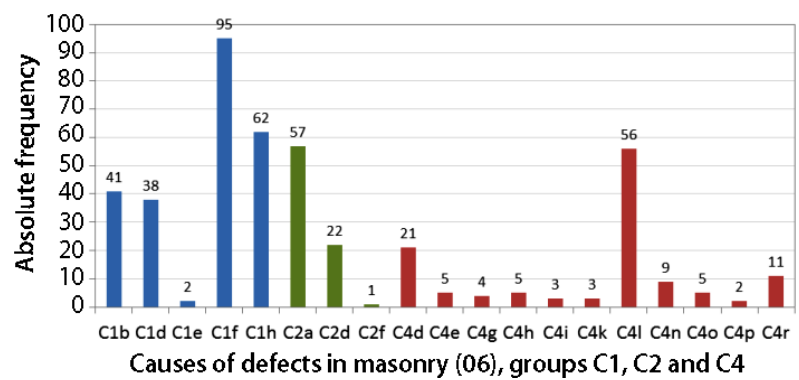

Fig. 17. Absolute frequency of the specific causes of anomalies in masonry (06) belonging to the general groups $\mathrm{C} 1, \mathrm{C} 2$ and $\mathrm{C} 4$

study deformations related to foundations' differential settlements are included in the design errors group of causes, while in the present study differential settlements belong to a specific group of causes associated to the structural behaviour of the building (C1). Nevertheless, the above mentioned specific cause is the most often diagnosed in both studies. Furthermore, in general, the results of the two studies are in agreement.

Besides the referred causes, oriented cracking (A5) in masonry elements is triggered by previous defects. The main previous defect is malfunctioning (A19). The same condition is found for oriented cracking (A5) in general (regardless of the construction element) (Fig. 18) and this defect is frequently related to expansion joints. In the case studies, expansion joints between structural elements are frequently deficiently executed regarding their geometry and filling. Proper functioning of expansion joints depends on the following aspects: geometry; adequate elasticity of the sealant; and proper application of the sealant, regarding the depth of the flexible foam spacer location and adhesion to the substrate. Some expansion joints require protection elements, namely in pavements. Most of these good construction practice rules were ignored in the case studies.

In the walls analysed it is common that the joint between the last row of masonry blocks and the beam is totally filled with mortar. This type of confinement and the volume changes of the masonry blocks due to water absorption or temperature variations can cause cracking (Fathy et al. 2009). The connections between structural 


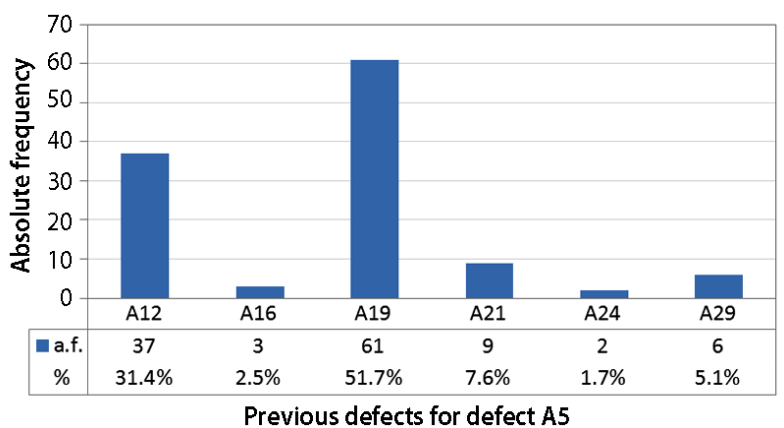

Fig. 18. Absolute frequency (a.f.) and percentage of previous defects for defect A5 - linear cracking

elements and masonry walls require an adequately designed gap filled with a flexible material, which was very seldom observed in the case studies. This avoids excessive stiffness in the connection between elements (C4l), one of the main causes for oriented cracking in masonry elements (Fig. 17). These joints prevent the build-up of internal stresses in the materials in service that may lead to disconnections and cracks.

The mortar used to build a masonry wall has a great influence on its performance. Hardened mortar must be sufficiently strong and guarantee adequate adhesion to the blocks. It is also relevant that the mortar sets without excessive shrinkage. This would decrease resistance of the masonry to rain penetration and cause cracking of the units. The mortar must have some workability that allows the accommodation of movement in the masonry resulting from thermal effects without cracking (Hendry 2001). Again, these common practice rules were not duly considered in many case studies, especially those where the incidence of anomalies in the mortars was higher.

\subsection{Paintings}

Besides being very frequent in concrete elements and masonry, oriented cracking (A5.b) is also one of the most often diagnosed defects in paintings. Oriented cracking in paintings frequently results from previous cracking in the substrate constructive elements and coatings (codes A5 and A5.a respectively). This condition justifies the high frequency of oriented cracking in paintings. Defects spalling (A8) and blistering (A31) also stand out in this construction element (Fig. 19).

The main causes for defects in paintings are environmental $(\mathrm{C} 2)$, structural $(\mathrm{C} 1)$ and related to project or construction errors (C4) (Fig. 20). The specific causes that stand out within each main group are the following: presence of humidity $(\mathrm{C} 2 \mathrm{~d})$ and thermo-hygrometric effects (C2a), differential settlements (C1f), excessive deformation of structural elements (C1d), malfunctioning of expansion joints (C1b) and disconnections (C1h), excessive stiffness in the connection between elements.

The main causes for defects in paintings are environmental (C2), structural (C1) and related to project or construction errors (C4) (Fig. 20). The specific causes that stand out within each main group are the following: presence of humidity $(\mathrm{C} 2 \mathrm{~d})$ and thermo-hygrometric effects (C2a), differential settlements (C1f), excessive deformation of structural elements (C1d), malfunctioning of expansion joints $(\mathrm{Clb})$ and disconnections $(\mathrm{C} 1 \mathrm{~h})$, excessive stiffness in the connection between elements (C4l), faulty waterproofing (C4i) and faulty drainage (C4g) (Fig. 21). Causes C2d, C4i and $\mathrm{C} 4 \mathrm{~g}$ are more related to spalling (A8) and blistering (A31). These types of defects establish a chain of pathological events. Blistering is the main previous defect for spalling in paintings and spalling is the only consequent defect identified for blistering. Infiltrations (A21) are also crucial to the occurrence of both types of defects. The presence of moisture inside the materials' porous structure leads to their degradation. It may be responsible for several decay processes, such as soluble salts crystallisation cycles (Gentilini et al. 2012). When salt crystallisation takes place in the pores of the material crypto-efflorescence occurs. The pressure caused inside the porous structure may

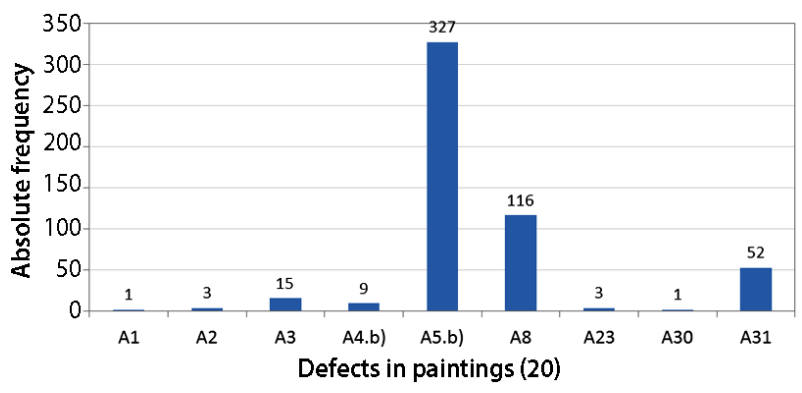

Fig. 19. Absolute frequency of defects in paintings (20)

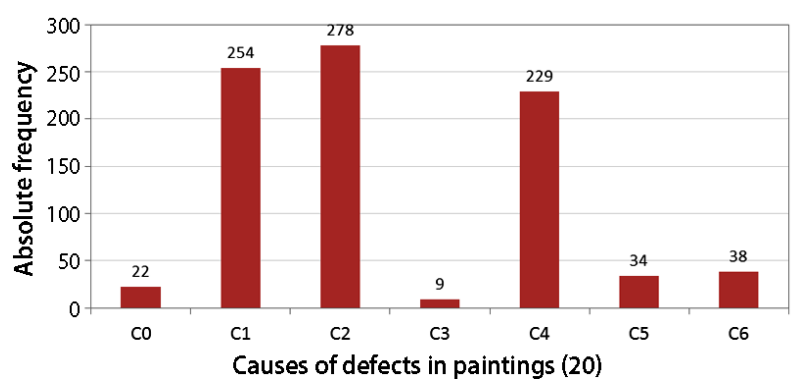

Fig. 20. Absolute frequency of the general groups of causes in paintings (20)

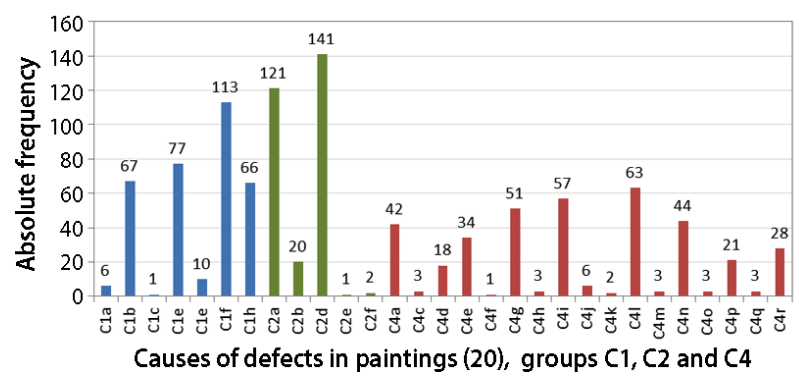

Fig. 21. Absolute frequency of the specific causes of anomalies in paintings (20) belonging to general groups $\mathrm{C} 2$ $\mathrm{C} 1$, and $\mathrm{C} 4$ 
induce the rupture of the pores walls leading to anomalies such as pulverisation, crumbling, blistering and flaking. Other damages can occur, such as peeling of paints and detachment of plasters and renders (Gonçalves et al. 2009; Pires et al. 2015).

Generally, the presence of stains is common in the case studies. Stains are frequently related to the presence of humidity that may also trigger biological colonization. This latter defect was not significantly registered in the case studies (only $4.2 \%$ of frequency) or specifically in paintings. However, it occurs in all buildings. The visual observation during the inspections and the analysis of the data of the schools degradation condition allow concluding that biological colonization exists in a considerable number of exterior painted surfaces. The study revealed a trend for biological colonization and stains in North facing facades. In Europe, North and West facing surfaces may be more colonised by phototrophic organisms than other surfaces (Gaylarde et al. 2011). North facing facades are more affected by biological colonization because they are cooler and dry slower after rain. The growth of microorganisms is influenced by hygrothermal conditions, and requires high humidity levels or condensation. A combination with high temperatures also favours growth. The formation of a microbial bio film over painted surfaces leads to change of properties such as brightness, smoothness, hydrophobicity, heat and water retention and, in a long-term, reduces their durability. The microbial colonization of paintings causes aesthetic problems and can lead to degradation, blistering, flaking and spalling of the coating (Gaylarde et al. 2011). Some cases of paint spalling were identified in metallic elements and these were most often related to corrosion. The permeability of paint plays an important role in the metallic substrate corrosion, since this property is directly connected with the penetration of environmental corrosion-inducing chemicals through the polymeric matrix and pores, voids or other defects in the coating (Elsner et al. 2003). It is also relevant that water and oxygen can permeate, at least to some extent, even if neither of those intrinsic structural defects is present. The effectiveness of a paint system depends on the method and quality of the surface preparation. In steel surfaces, debris such as oxides, dirt, dust, grease, oil, old paint, corrosion products, rust, moisture and/or mill scale, and other foreign matter are determinant for the adhesion of paint. When any of these materials is painted over, it interferes with the mechanical and chemical adhesion of the paint film to the substrate, promoting the coating failure. These materials may allow water or water vapour through the paint film and cause paint blistering and/or delamination and also accelerated corrosion of the underlying steel. The most severe cases of corrosion noticed in the case studies were related to the infringement of good practice rules both at the initial construction stage and the maintenance stage. Specifically in metallic elements lack of proper and regular maintenance was particularly felt.

\subsection{Coatings}

The type of coating most affected by defects is interior rendering (10.01) (Fig. 22). Oriented cracking (A5.a) and stains (A3) are the types of defects more frequently diagnosed in this coating (Fig. 23). According to a study about wall renderings developed by Sá et al. (2015) (Fig. 24), linear cracking (A-M3) is the second main type of defect likely to be found in the interior surface of walls. The same study is more specific regarding the categorization of the types of defects. Dirt/particle deposit (A-E2) and infiltration/damp stains (A-H1) is similar to defect A3 (discoloration or stain) considered in our analysis. Stains, regardless the specificity of their origin, are also quite likely to occur in the interior surface of walls.

Oriented cracking (A5.a) and stains (A3) are also respectively the first and second types of defects more often diagnosed in all types of wall coatings (Fig. 23). This condition is also found in the study of Sá et al. (2015) on wall renderings (Fig. 24), although dirt/particle deposit (A-E2) also stands out. The study developed by Gaspar and de Brito (2005) on defect sensitivity in external mortar renders reveals similar results. Cracking due to differential movements (structure and wall) is the most common type of defect ( $31 \%$ of occurrences), followed by problems related to driving rain and surface water flow through the facade $(25 \%)$. Cracking due to other durability problems (such as shrinkage of the render or sulphate ion attack in the presence of water) represents $12 \%$ of the identified defects, shortly followed by damp staining and infiltration (11\%).

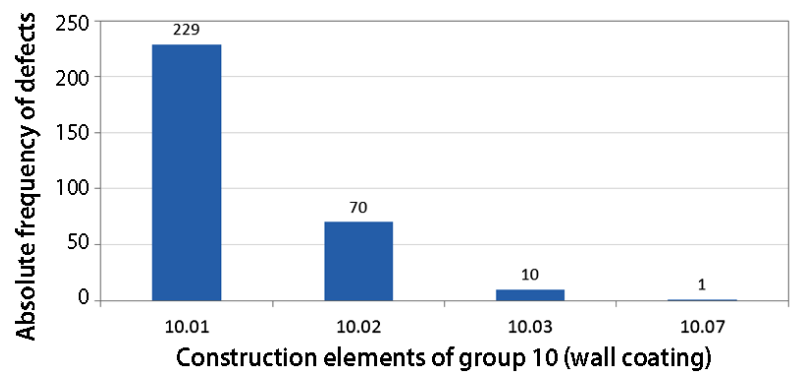

Fig. 22. Absolute frequency of defects according to the specific construction elements belonging to group 10 - wall coatings

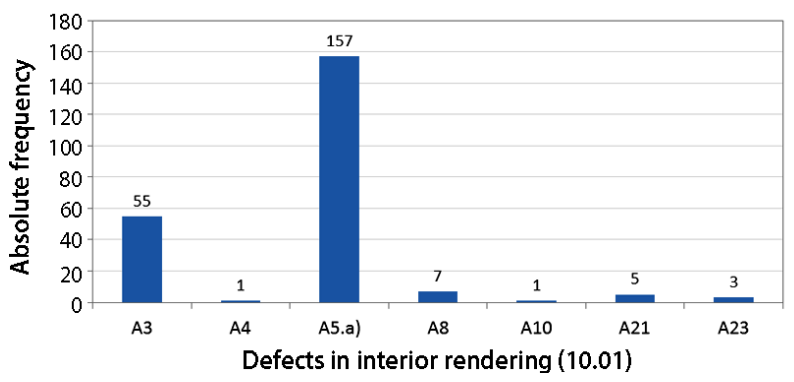

Fig. 23. Absolute frequency of defects in interior rendering (10.01) 
The main causes of defects in coatings (10) are similar to the ones identified in paintings (Fig. 25). However, in this case the absolute frequency of causes related with the structure of the building $(\mathrm{C} 1)$ is higher than that of environmental causes (C2). The specific causes differential settlements (C1f), thermo-hygrometric effects (C2a), humidity (C2d) and excessive stiffness in the connection between elements (C41) (Fig. 26) stand out. All these causes are directly related to the manifestation of oriented cracking (A5), except for humidity (C2d). This latter cause is more associated to the occurrence of stains (A3). In the study developed by Sá et al. (2015) causes related to environmental actions are the most frequent (42\%). This result was expected considering that most of the inspected renderings are external and therefore more exposed to the aggression of the environment throughout their service life. In our analysis, environmental causes are also relevant, despite the fact that most of the defects diagnosed in renderings are in interior surfaces. The presence of water/water vapour and high relative humidity are part of the most significant group of specific causes associated to environmental actions. The same can be said about our analysis.

In the study of Sá et al. (2015) on wall renderings, design errors and execution errors represent $18 \%$ and $15 \%$ of the causes identified for the defects detected, respectively. In our analysis, causes linked to the design or construction phases (C4) also stand out (Fig. 25).

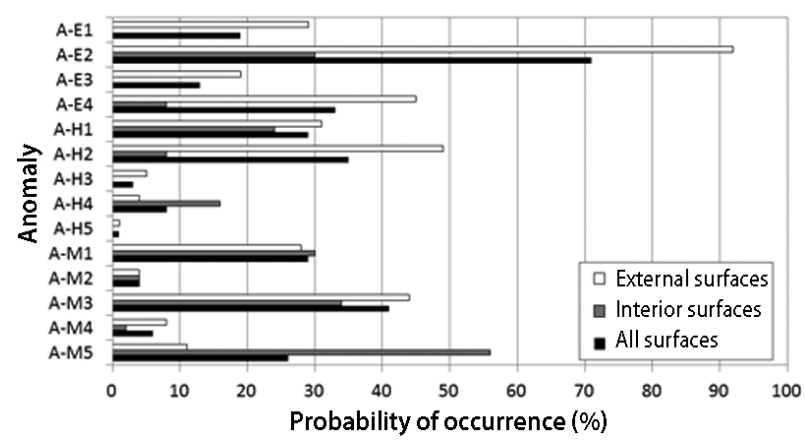

Fig. 24. Probability of finding each anomaly in one wall considering external surfaces, interior surfaces and all surfaces (adapted from Sá et al. 2015)

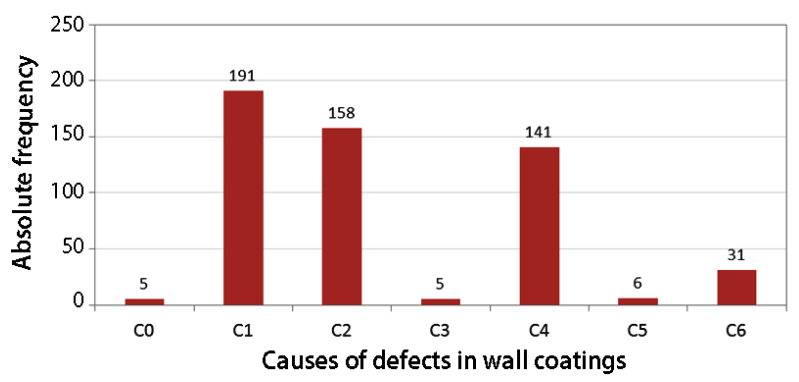

Fig. 25. Absolute frequency of the general groups of causes in wall coatings (10)

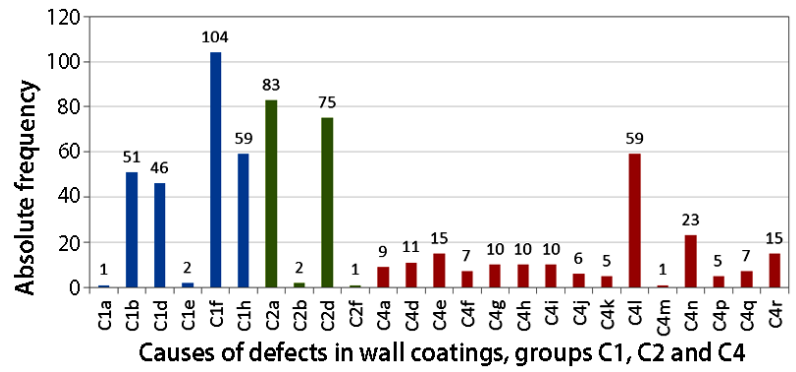

Fig. 26. Absolute frequency of the specific causes of anomalies in wall coatings (10) belonging to general groups $\mathrm{C} 1, \mathrm{C} 2$ and $\mathrm{C} 4$

\subsection{Stains}

The severity of the defects diagnosed in the buildings' envelope and the considerable frequency of stains (A3) diagnosed in the interior areas indicate that the buildings do not effectively protect the inner space from the external agents. The occurrence of stains frequently implies the presence of humidity due to infiltrations (Fig. 27). Infiltrations (A21) are the main previous defects for stains (Fig. 27), and are more likely to occur in ceiling coatings (12), wall coatings (10) and concrete elements (03) (mostly in reinforced concrete beams at the top of the pavilions and roof slabs) (Figs 28 and 29). The main causes of stains are deficiencies related to the waterproofing system $(\mathrm{C} 4 \mathrm{i})$, detailing $(\mathrm{C} 4 \mathrm{n})$, drainage $(\mathrm{C} 4 \mathrm{~g})$ and building end profiles (C4a) (Fig. 30). The results presented allow concluding that the roofing systems need considerable repair. Simultaneously, it is necessary to remove all the corrugated fibrocement roof plates. Currently, the use of this material (no longer manufactured/applied) is forbidden since it does not fulfil health requirements established for education facilities, because it incorporates asbestos (nowadays replaced by natural fibres). Most of the infiltrations are solved only through the renovation of the entire roof, based on the adequate implementation of current systems and techniques.

The roof area and the gutters must have a minimum slope to ensure an efficient drainage. The minimum slope of a pitched (tiled) roof depends on the following factors: type of tile used; exposure conditions; geographic location and location in the roof plan (Sousa et al. 1998). Generally, the minimum slopes vary between $32 \%$ and $96 \%$. Flat roofs must have a minimum slope of $2 \%$. In the case studies, some of the roofs may not have the minimum required slopes. This situation leads to the accumulation of debris on the surface of the roofs hindering rainwater drainage. The correct drainage of the roof also implies that the gutters are well designed and debris free. The drain pipes must be protected at the top with drainage grids (to avoid clogging due to debris accumulation). Frequently these protections are missing from the analysed schools' roofs. This is one of the most frequent reasons for drainage problems.

The defects diagnosed in roofs that tend to cause infiltrations are associated to drainage problems, but 
also to the waterproofing systems as mentioned above. Frequently, the water tightness is compromised by the incorrect positioning of the water-proofing membrane, particularly in vertical plans and singular points where prominent elements intersect the roof's plan. This situation occurs frequently in the case studies, mostly in chimneys and peripheral walls. Incorrect application of waterproofing membranes is common in repaired areas of the roofs. Bituminous waterproofing membranes must be completely adhered to the referred elements, through welding torch flame, and include additional mechanical fastenings when the height of the membrane is higher than $40 \mathrm{~cm}$. The expansion joints in roofs must be correctly waterproofed through the application of a flexible foam cord or mastic, with a suitable cross-section, to support the waterproofing membrane that must be reinforced in this area by overlapping membranes. The water tightness may also be compromised due to the aging process of the waterproofing membranes. Roofing materials are exposed to environmental actions, such as

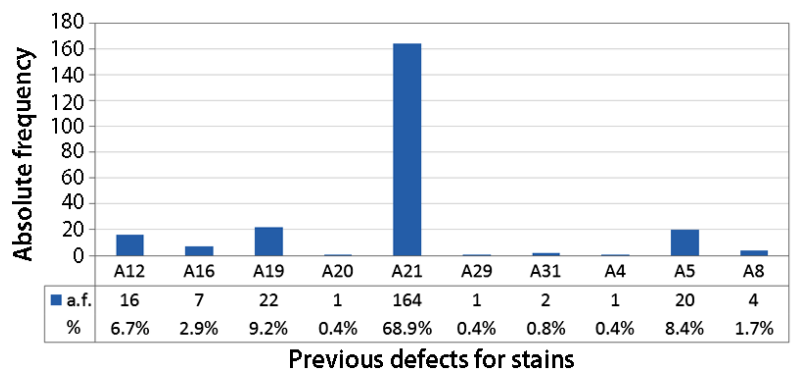

Fig. 27. Absolute frequency (a.f.) and percentage of previous defects for stains (A3) in the case studies

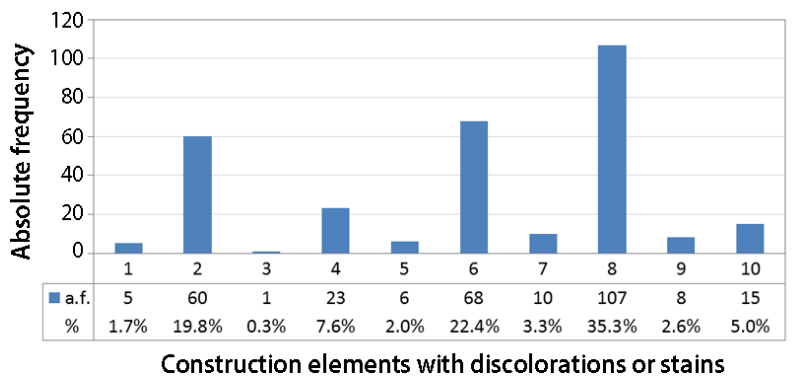

Fig. 28. Absolute frequency (a.f.) and percentage of construction elements with discolorations or stains (A3)

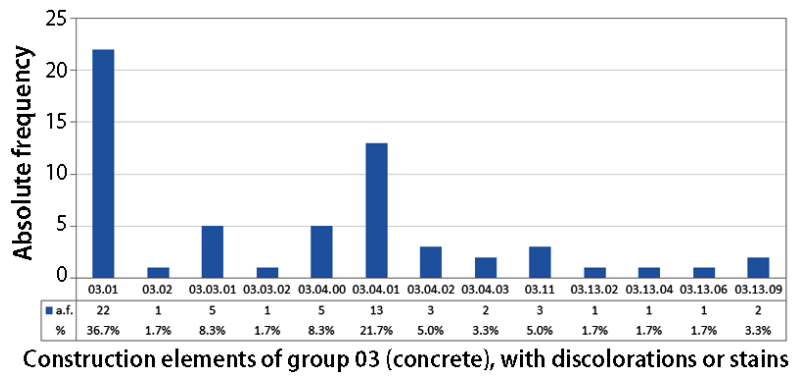

Fig. 29. Absolute frequency (a.f.) and percentage of specific construction elements belonging to group 03 - concrete elements with discolorations or stains (A3)

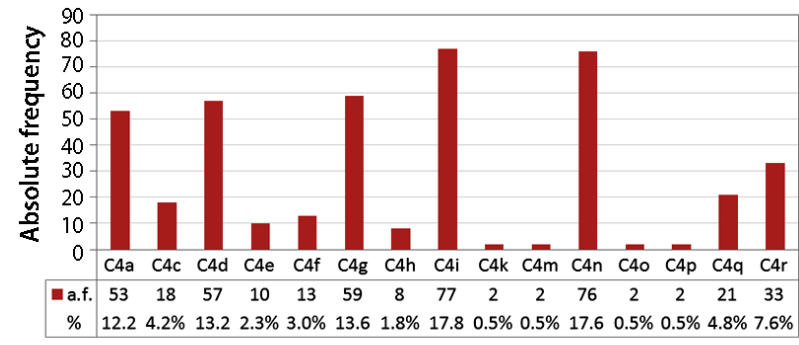

Causes of defects of group C 4 for stains

Fig. 30. Absolute frequency and percentage of specific causes belonging to group $\mathrm{C} 4$ for stains (A3)

wind, sunlight, rain, hail, atmospheric pollution and temperature variations. Despite their level of durability, materials are modified by deposition of dust and debris and may be colonized by biological organisms. The photons, of which sunlight is composed of, can break many chemical bonds, especially in organic materials. For example, plastics, wood and asphalt are all organic materials composed largely of carbon and hydrogen atoms linked into chains, rings, and more complex structures. These materials are altered by ultraviolet radiation, usually followed by oxidation. As a result of oxidation, asphalt becomes harder and stiffer. If the asphalt substrate is adequately covered by granules, the photo-oxidation process can be largely prevented (Berdahl et al. 2008). Given the limited durability of all these materials, the lack of maintenance, which was very rarely or never performed in the flat roofs of the case studies analysed, is identified as the main cause for the general degradation found in these materials.

Water running down the building surfaces due to drainage deficiencies or to ineffectiveness or absence of flashing drip details $(\mathrm{C} 4 \mathrm{~d})$ is one of the main causes of stains (Fig. 30). Correct detailing of the roof toppings is essential to avoid that. The roof top must include a stone or zinc coping. These elements must have an adequate slope to ensure correct water drainage and must be provided with flashing drip detailing. In the vast majority of the case studies the detailing of most constructive elements was simply defective and that was found to promote the degradation observed.

\section{Conclusions}

The degradation of the pavilion schools analysed in this paper was caused mainly by lack of construction quality, resulting from decisions made during the design and construction processes. It can be concluded that the time and economic conditions associated to the production of schools from this specific period led to a set of constructive problems. They contributed to the occurrence of defects that characterize the pathological conditions of the case studies. Within this scope the following aspects are highlighted: deficient detailing of constructive solutions; inefficiency or absence of building end profiles; absence of coatings and finishes; and questionable quality of 
some materials. The lack of investment in the quality of the structure, characterized by insufficient concrete cover, is also evident. The conditions presented, emphasized by the absence of maintenance plans, indicate some negligence regarding the durability of these buildings and their performance over time.

The analysis of the case studies historical overview, constructive features, location and diagnosed defects provided a better understanding of the schools' pathological condition. The statistical analysis allowed concluding that if some measures related to the design and construction of the buildings had been initially considered, the present degradation condition of the schools could be less severe. However, there are other types of causes behind the schools' pathological profile, such as structural and environmental causes. The incorrect consideration of the buildings' location and environmental context, regarding their exposure conditions, has also contributed to their premature degradation. The development of a school project must be a meticulous process based on the quality of the buildings' performance along their service life. The implementation of maintenance plans is crucial to guarantee this condition (Paulo et al. 2013).

The statistical results obtained about the degradation conditions of the schools and the factors that determine their pathological profile are the starting point to reflect about and develop rehabilitation strategies to apply to this school building typology. The analysis presented contributes to the improvement of the defects repair process, avoiding the repetition of previous mistakes.

\section{References}

Alegre, A. 2009. Architecture for secondary schools in Portugal: principles and evolution over the XX century, in $A A$. $V V$., Secondary schools - rehabilitation. Lisbon: Caleidoscópio (in Portuguese).

Alegre, A.; Heitor, T.; Cotrim, H.; Vaz, D.; Silva, J. C.; Silva, J. F. 2010. Lyceums technical schools and secondary schools. Lisbon: Parque Escolar (in Portuguese).

Aveldaño, R.; Ortega, N. 2011. Characterization of concrete cracking due to corrosion of reinforcements in different environments, Construction and Building Materials 25(2): 630-637.

http://dx.doi.org/10.1016/j.conbuildmat.2010.07.029

Berdahl, P.; Akbari, H.; Levinson, R.; Miller, W. A. 2008. Weathering of roofing materials - an overview, Construction and Building Materials 22(4): 423-433. http://dx.doi.org/10.1016/j.conbuildmat.2006.10.015

Branco, F.; de Brito, J.; Ferreira, J.; Correia, J. R.; Roriz, L.; Paulo, P.; Flores-Colen, I. 2008. Reports on the construction defects of secondary schools. ICIST Re-ports, Lisbon, 2008 (in Portuguese)

Elsner, C. I.; Cavalcanti, E.; Ferraz, O.; Di Sarli, A. R. 2003. Evaluation of the surface treatment effect on the anticorrosive performance of paint systems on steel, Progress in
Organic Coatings 48(1): 50-62.

http://dx.doi.org/10.1016/S0300-9440(03)00112-7

EN 1992-1-1. 2004. Eurocode 2: Design of concrete structures Part 1-1: General rules and rules for buildings. European Committee for Standardization (CEN), Brussels.

Fathy, A. M.; Planas, J.; Sancho, J. M. 2009. A numerical study of masonry cracks, Construction and Building Materials 16(2): 675-689.

Gaspar, P.; de Brito, J. 2005. Mapping defect sensitivity in external mortar renders, Construction and Building Materials 19(8): 571-578.

http://dx.doi.org/10.1016/j.conbuildmat.2005.01.014

Gaylarde, C. C.; Morton, L. H. G.; Loh, K.; Shirakawa, M. A. 2011. Biodeterioration of external architectural paint films - a review, International Biodeterioration \& Biodegradation 65(8): 1189-1198. http://dx.doi.org/10.1016/j.ibiod.2011.09.005

Gentilini, C.; Franzoni, E.; Bandini, S.; Nobile, L. 2012. Effect of salt crystallisation on the shear behaviour of masonry walls - an experimental study, Construction and Building Materials 37: 181-189.

http://dx.doi.org/10.1016/j.conbuildmat.2012.07.086

Gonçalves, A.; de Brito, J.; Branco, F. 2008. Causes of anomalies in recent buildings masonry walls, Engenharia Civil UM 31: 5-18 (in Portuguese).

Gonçalves, T. D.; Pel, L.; Rodrigues, J. D. 2009. Influence of paints on drying and salt distribution processes in porous building materials, Construction and Building Materials 23(5): 1751-1759.

http://dx.doi.org/10.1016/j.conbuildmat.2008.08.006

Heitor, T. 2009. Modernising secondary schools, in $A A$. $V V$., Secondary schools - rehabilitation. Lisbon: Caleidoscópio (in Portuguese).

Hendry, E. A. W. 2001. Masonry walls: materials and construction, Construction and Building Materials 15(8): 323-330. http://dx.doi.org/10.1016/S0950-0618(01)00019-8

LNEC. 2005. Specification LNEC - E 464-2005, Concrete, Methodology for 50 years of service life regarding environmental exposure (in Portuguese).

Nunes, J. S.; Heitor, T. 2010. Schools' Rehabilitation, in $\mathrm{Na}$ tional Meeting on Conservation and Rehabilitation of Structures - Reabilitar 2010, APEE, LNEC, OE, Lisbon Portugal (in Portuguese).

Paulo, P.; Branco, F. A.; de Brito, J. 2013. BuildingsLife, a building management system (BdMS), Structure and Infrastructure Engineering 10(3): 388-397. http://dx.doi.org/10.1080/15732479.2012.756919

Pires, R.; de Brito, J.; Amaro, B. 2015. Statistical survey of the inspection, diagnosis and repair of painted rendered façades, Structure and Infrastructure Engineering 11(5): 605-618. http://dx.doi.org/10.1080/15732479.2014.890233

Sá, G.; Sá, J.; de Brito, J.; Amaro, B. 2015. Statistical survey on inspection, diagnosis and repair of wall renderings, Journal of Civil Engineering and Management 21(5): 623636. hettp://dx.doi.org/10.3846/13923730.2014.890666

Sousa, A.; Abrantes, V.; Silva, M.; Moura, G. I.; Silva, R. M.; Freitas, V.; Sousa, H. 1998. Ceramic tiles application manual. Coimbra: Portuguese Association of Ceramics and Construction Entrepreneurs (in Portuguese).

Takewaka, K.; Yamaguchi, T.; Maeda, S. 2003. Simulation model for deterioration of concrete structures due to chloride attack, Journal of Advanced Concrete Technology 1(2): 139-146. http://dx.doi.org/10.3151/jact.1.139 


\section{Appendix}

\section{List of acronyms}

\section{A) Construction elements}

01 external pavements and drainage; 02 external construction elements; 03 concrete elements; $\mathbf{0 3 . 0 1}$ reinforced concrete beams at the top of the pavilions; 03.02 reinforced concrete columns; 03.03.00 reinforced concrete beams; 03.03.01 reinforced concrete roof beams; $\mathbf{0 3 . 0 3 . 0 2}$ reinforced concrete beams in intermediate floors; $\mathbf{0 3 . 0 3 . 0 3}$ reinforced concrete beams in external elements; 03.04.00 slabs; 03.04.01 roof slab; 03.04.02 slab under pitched roof; 03.04.03 slab between floors; 03.04.04 ground floor slab; 03.04.05 external porch slab; 03.05 concrete base slab; 03.06 concrete sills and doorsteps; 03.07 concrete jambs and lintels; 03.11 concrete roof eaves; 03.12 concrete external stairs; $\mathbf{0 3 . 1 3 . 0 2}$ concrete external platbands; 03.13.04 concrete external protruding panel support; 3.13 .05 concrete vertical plates; 03.13 .06 concrete interior stairs; 03.13 .09 precast concrete panels; 04 steel structure; 05 wood structure; 06 masonry; 06.01 external masonry cavity walls; $\mathbf{0 6 . 0 2}$ simple masonry walls; 06.03 uncoated brick walls; $\mathbf{0 6 . 0 6 . 0 1}$ roof walls; 06.06 .03 walls of autoclaved aerated concrete blocks; 08 stonework; 09 expansion joints; 10 wall coatings; 10.01 interior rendering; $\mathbf{1 0 . 0 2}$ external rendering; $\mathbf{1 0 . 0 3}$ glazed ceramic tiles; $\mathbf{1 0 . 0 7}$ non-glazed ceramic tiles; 11 floor coatings; 12 ceiling coatings; 14 pitched roofs coatings; 15 flat roofs; 17 woodwork; 18 metalwork; 19 glass and mirrors; 20 paintings; 22 plumbing and equipment.

\section{B) Defects}

A1 differential dirt; $\mathbf{A 2}$ uniform dirt; A3 discoloration or stain; A4 mapped cracking; A5 linear cracking; A7 fracture or broken element(s); A8 spalling, peeling or flaking; A9 alveolization or pits; A10 in depth lacuna; A12 corrosion; A14 loose element(s); A16 missing element(s); A17 localized wear; A18 uniform wear; A19 malfunctioning; A20 nonfunctioning; A21 infiltration; A22 concretion; A23 biological attack or colonization; A24 parasitic vegetation; A25 bird droppings; A28 debris; A29 excessive deformation/settlements; A30 graffiti; $\mathbf{A 3 1}$ blistering.

\section{C) Causes of defects}

C0 causes of unknown nature; C1 structural causes; C1a deficient steel reinforcement cover; C1b malfunctioning of expansion joints; C1c low concrete strength; C1d excessive deformation of structural elements; C1e excessive loading; C1f differential settlements; C1h disconnections; C2 environmental causes; C2a thermo hygrometric effects; C2b exposure to wind, rain and pollution; C2c drying $\mathbf{C 2 d}$ presence of humidity; C2e chloride penetration; C2f efflorescence; $\mathbf{C} \mathbf{3}$ causes related to time/aging; $\mathbf{C} \mathbf{4}$ causes related to design or construction; $\mathbf{C 4 a}$ deficiencies related to building end profiles; $\mathbf{C 4 c}$ architectural shape of external elements; $\mathbf{C 4 d}$ water running down surfaces due to deficiencies related to drainage and/or flashing drip details; C4e faulty dimensioning; $\mathbf{C 4 f}$ thermophorese stains; $\mathbf{C 4 g}$ faulty drainage; $\mathbf{C} 4 \mathbf{h}$ faulty execution; $\mathbf{C 4} \mathbf{i}$ faulty waterproofing; $\mathbf{C 4 j}$ shrinkage; $\mathbf{C 4 k}$ faulty repair; $\mathbf{C 4 l}$ excessive stiffness in the connection between elements; $\mathbf{C 4 m}$ faulty finish or protection; C4n deficiencies related to detailing; $\mathbf{C 4 0}$ water splashes; $\mathbf{C 4 p}$ faulty filling and/or finish of expansion joint; $\mathbf{C 4 q}$ faulty ventilation; $\mathbf{C 4 r}$ lack of tightness to aggressive external agents; $\mathbf{C 5}$ human or animal causes; $\mathbf{C} 6$ accidental causes.

Joana BARRELAS. She holds a degree in Architecture and a Master's degree in Construction and Rehabilitation from Instituto Superior Técnico, Technical University of Lisbon, Portugal. Her research interests include building pathology, in particular of school facilities.

Jorge DE BRITO. He is a Full Professor at Instituto Superior Técnico, Technical University of Lisbon, Portugal. He is a member of CIB W80, W86 and W115. His research interests include the performance, pathology, in situ testing, diagnosis, maintenance, rehabilita-tion and service life prediction of buildings and construction elements and sustainable construction.

João Ramôa CORREIA. He is an Associate Professor at Instituto Superior Técnico, Technical University of Lisbon, Portugal. He is a member of CIB W86. His research interests include the performance, pathology, in situ testing, diagnosis, maintenance and rehabilitation of buildings and construction elements. 